\section{LO SUBLIME EN EL PAISAJE ANTRÓPICO A TRAVÉS DE LA FOTOGRAFÍA ACTUAL}

\author{
María Antonia Blanco Arroyo \\ Universidad de Sevilla \\ mblanco8@us.es \\ ORCID iD: http://orcid.org/0000-0002-4612-5365
}

\section{THE SUBLIME IN THE ANTHROPIC LANDSCAPE BY MEANS OF MODERN PHOTOGRAPHY}

Cómo citar este artículo/Citation: Blanco Arroyo, M. A. (2017). Lo sublime en el paisaje antrópico a través de la fotografía actual. Arbor, 193 (784): a388. doi: http://dx.doi.org/10.3989/ arbor.2017.784n2010
Copyright: (c) 2017 CSIC. Este es un artículo de acceso abierto distribuido bajo los términos de la licencia Creative Commons Attribution (CC BY) España 3.0.
RESUMEN: En este artículo se desarrolla un análisis conceptual de lo sublime, acaparando el paisaje antrópico como campo de actuación, y ambas proyecciones se inscriben dentro de la disciplina de la fotografía. Así pues, se plantea un recorrido narrativo a través de la creación fotográfica de las últimas décadas, para abordar la naturaleza sublime y lo sublime industrial en la actualidad. Las constantes conceptuales advertidas en los diversos discursos artísticos marcan la línea argumental de este artículo, para establecer un marco teórico en torno a la existencia humana en el paisaje post-industrial que nos acontece. La selección de artistas incluidos, constituye un hilo conductor clave sobre el que examinar la evolución y transformación de conceptos universales presentes en el contexto paisajístico actual; algo que nos proporciona una conceptualización actualizada sobre la relación del ser humano con su entorno alterado.

PALABRAS CLAVE: Paisaje; fotografía; sublime; belleza; naturaleza.
ABSTRACT: This article expounds on a conceptual analysis of the sublime, employing the anthropic landscape as the field of study, and registering both projections within the discipline of photography. Therefore, a narrative is formulated with the photographic production from the last few decades, in order to address both sublime nature and the current day industrial sublime. The conceptual constants from several artistic discourses define the line of argument running through this article to establish a theoretical framework for human existence in today's post-industrial landscape. The artists selected provide a crucial unifying thread permitting the evolution and transformation of universal concepts of landscape to be examined; providing us with an updated conceptualization of the relationship between humans and their altered environment.

KEYWORDS: Landscape; photography; sublime; beauty; nature. 


\section{INTRODUCCIÓN}

Analizar el paisaje antrópico en el mundo actual, híbrido y cambiante, implica mirar más allá de la corteza visual de la imagen, para profundizar en su entramado estético y conceptual, pues la progresiva transformación del entorno que habitamos nos revela cuestiones clave de la vida humana. Debemos concebir el paisaje como una confluencia de elementos y acontecimientos que van modelando nuestro destino. Éste es un hecho reflejado de forma sublime en la creación fotográfica de las últimas décadas, un lenguaje artístico que se convierte en una fuente de conocimiento plural. Por tanto, en este artículo, trataremos de hilar una teoría sobre el proceso paisajístico de reconstrucción continua que nos acontece, a través de la obra de ciertos fotógrafos contemporáneos. De hecho, en el actual siglo XXI, estamos inmersos en un proceso de imparable transformación, en el que la cualidad prístina de la naturaleza ha sido reemplazada por la mano del hombre, y esta observación nos posiciona en un estado de reflexión continua sobre la evolución del paisaje.

Según los últimos estudios, el paisaje ha evolucionado hacia una nueva etapa que el premio nobel de química Paul Crutzen ha anunciado con el nombre de antropoceno. Esta nueva acepción histórica es una continuación del proceso de transformación del entorno, algo que hasta ahora solo había sido posible mediante la acción de la naturaleza. El pleistoceno fue un periodo muy frío, de numerosas glaciaciones, y cuyo desarrollo tuvo cabida mucho antes de cualquier atisbo de civilización. El pleistoceno, hace algo así como unos 11.000 años, daría paso al holoceno, un nuevo periodo caracterizado por un clima más templado y que propició algo de suma importancia para el hombre: el nacimiento de la agricultura. Ahora, sin embargo, podríamos estar inmersos en el inicio de una nueva etapa que, según Paul Crutzen, comenzó a desarrollarse a finales del siglo XVIII con la industrialización. La gran pregunta es si la humanidad por sí misma es capaz de conformarse como un agente transformador de tales proporciones. El escritor William L. Fox así lo cree, por lo que ha desarrollado sus teorías al respecto, considerando el "antropoceno" como un nuevo periodo, en el que la existencia humana se concibe como el mayor agente geológico de transformación de nuestro paisaje (Ellsworth y Kruse, 2013). Este hecho ha estado presente en el pensamiento y en la obra de notables fotógrafos y alcanza un auge significativo en la actualidad, introduciéndonos en una nueva disertación plástica y social de la imagen fotográfica.
Se puede decir que hoy la fotografía refleja las huellas de un mundo construido y modificado por el hombre, un proceso de reinvención paisajística inscrito en el sistema de la sociedad post-industrial. Todas las acciones humanas definen el entorno natural y urbano y lo constituyen a sí mismo como paisaje. Este constructo espacio-temporal, en estado de transformación continua, constituye el paisaje antrópico del que formamos parte. A través de la fotografía es posible interpretar esta concepción paisajística y desentramar las constantes advertidas en numerosos discursos artísticos.

En los años 80, importantes fotógrafos contemporáneos, como Jeff Wall, Andreas Gursky, Gregory Crewdson, o Georges Rousse entre otros, recuperan la idea de imagen única. De este modo el clásico de la obra maestra parece experimentar una especie de reconocimiento. Además, este énfasis de imagen única ha desempeñado un papel históricamente importante en la emancipación de la fotografía como una expresión artística, así como en su relación formal con la historia de la pintura (Gronert, 2009). En 1980 Jeff Wall comienza a fotografiar paisajes, confirmando su deseo de acercar la fotografía a la pintura, y utiliza la caja de luz de gran formato, algo que otorga gran luminosidad y monumentalidad a sus transparencias. Wall adopta las reglas del género de la pintura de paisaje, aunque las altera eligiendo escenas donde la naturaleza aparece invadida por la industrialización y los suburbios. En su trabajo destaca las preocupaciones sociales y el interés narrativo de esos paisajes. Durante la década de los 80 a la que nos venimos refiriendo, en el ámbito norteamericano la fotografía fue proclamada como la actividad por antonomasia del postmodernismo. Sin embargo, teóricos como Benjamin Buchloh, Douglas Crimp, y sobre todo Rosalind Krauss o Pierre Bourdieu en Europa, creían que la vuelta al medio expresivo no se trataba de un discurso estético, sino de un proyecto de deconstrucción, que acabaría finalmente con el aura y la originalidad. Según expresa Andreas Gursky:

\footnotetext{
“En los años 70, al menos en Alemania, la fotografía no formaba parte de las artes plásticas ... Lo que pensábamos en cualquier caso es que había que interpretar lo real para acceder a una expresión artística, fuera cual fuera. Cuando empecé mis estudios en Düsseldorf me interesó sobre todo la fotografía de la arquitectura. Al cabo de dos o tres años me consagré al paisaje." ${ }^{1}$
}

La fotografía de paisaje no solo documenta un hecho, pues la imagen de paisaje siempre alberga una connotación subjetiva que nos cuenta mucho más de lo que perciben nuestros ojos en un primer contacto 
visual. Robert Adams, que suscribe esta idea, afirma que las imágenes fotográficas de paisaje nunca son pura tautología, ya que el tema es demasiado profundo. No es posible abarcar todo un paisaje y capturarlo en una imagen, y por tanto no es viable concebir el paisaje fotografiado como una documentación aséptica del entorno (Adams, 1996). De acuerdo con esta idea, las narrativas intrínsecas dotan a la imagen de una caracterización conceptual, que nos permite profundizar de una manera más consciente en el paisaje antrópico fotografiado.

Cabría considerar que la fotografía de paisaje es también un modo de acercarse al conocimiento del propio pasado. Igual que la literatura, el paisaje nos acerca a los caracteres de las tradiciones culturales, y de una manera decimonónica, quizás al espíritu de los hombres y de los pueblos, tal y como sostiene Alexander von Humboldt en el planteamiento romántico (Álvarez Areces, 2009). Concibamos, pues, la fotografía como una posibilidad de conectar con la cultura y el pensamiento humano; por ejemplo, con la cultura de la industrialización, símbolo esencial de la transformación social del paisaje. Cabe destacar cómo la fascinación modernista por las factorías, chimeneas, montacargas de grano y minas es reflejada en muchas fotografías de paisajes industriales realizadas durante la década de los años 1920 y 1930. Son muy conocidos y relevantes los trabajos de los siguientes artistas: Edward Weston, Charles Sheeler, Margaret Bourke-White, Charles Burchfield, y William Gropper, entre otros. Estos autores confirman el gran interés del paisaje industrial (Pauli, 2003). También se ha de subrayar la notable ingravidez y abstracción que el fotógrafo estadounidense Brett Weston, hijo de Edward Weston, expresa en obras como Locomotive (locomotora) de 1927. Las imágenes de estos autores simbolizan la imparable transformación industrial del paisaje, que reverberará en la creación fotográfica de artistas actuales esenciales como Andreas Gursky, Simon Roberts, John Pfahl, Joel Sternfeld, Kim Keever, Yannick Demmerle, Axel Hütte, Edward Burtynsky, Chris Round, Richard Misrach o, Roderik Henderson, entre otros. Todos ellos serán susceptibles de análisis en este artículo.

Desde las últimas décadas del siglo XX hasta la actualidad las obras de numerosos fotógrafos, muchos de ellos incluidos en este texto, han ido creando un entramado conceptual en torno al paisaje y el lugar del hombre en él. Las fotografías de dichos autores se retroalimentan y adquieren una relevante significación estudiándolas en conjunto, ya que es mediante la interrelación de los diversos discursos artísticos como llegamos a interpretar el paisaje antrópico actual, advirtiendo además en este un punto de inflexión en común: lo sublime como detonante clave para interpretar el contexto posthumano que nos acontece.

\section{LA NATURALEZA SUBLIME: MÁS ALLÁ DE LA BELLEZA}

Según el filósofo y ensayista ilatiano Remo Bodei, lo sublime se instaura como la imposibilidad de representar por medio de la imaginación ideas como el infinito o la libertad, ya que estos conceptos están desligados de toda imagen sensible concreta. De este modo, se desvanece aquel ideal de acabado perfecto, que describía lo bello como una forma totalmente definida en el mundo antiguo. La superioridad de lo sublime sobre lo bello radica en que pone el acento en las bases emotivas de nuestros conflictos y en el valor de nuestros límites (Bodei, 2011). Se podría decir que en el momento actual también se busca la belleza, aunque no a través de la perfección formal, sino mediante el poder expresivo y comunicativo de la imagen, que trasciende sus propiedades puramente estéticas para llegar a nuestra conciencia desde múltiples vías del conocimiento humano. En la fotografía lo sublime puede ser concebido como una acepción de belleza que transforma la percepción que tenemos del paisaje, algo relevante para comprender nuestra relación con el mundo.

Asimismo, gran parte de la imaginería del paisaje de las últimas décadas, reconoce las nociones tradicionales de lo sublime, el poder de la naturaleza para transmitir un sobrecogimiento genuino en virtud de su escala. Esta nueva percepción combina la conciencia del origen del concepto mismo en el romanticismo, una compasión por el escepticismo del pensamiento posmoderno, y un sentido de asombro en la superficie de la inefabilidad de la naturaleza. Así pues, esta compleja sensibilidad sustenta el trabajo de notables fotógrafos tales como el estadounidense Joel Sternfeld. Su fotografía titulada Approximately 17 of 41 Whales which beached and subsequently died, Florence, Oregon (encallaron alrededor de 17 de 41 ballenas, y posteriormente murieron, Florence, Oregón), registra un grupo de espectadores curiosos en el lugar de un incomprensible suicidio en masa de ballenas (Davis, 1999). En este caso, lo sublime se convierte en un sentimiento de dolor y terror, algo que se proyecta con frecuencia en muchas de las imágenes de gran formato y en color que realiza Sternfeld. Este artista ahonda en los aspectos más mundanos y adversos del paisaje, a través de ciudades abandonadas o pai- 
sajes estériles. Uno de sus libros más emblemáticos es American Prospects, de 1987, en el que se exploran los paisajes alterados por la mano del hombre en Estados Unidos. Considerado un fotógrafo pionero del color, Joel Sternfeld ha constituido una referencia crucial para otros artistas como Andreas Gursky o Thomas Struth, cuyas obras también son objeto de reflexión sobre lo sublime.

En conexión con lo anterior, prestemos atención al discurso poético de Andreas Gursky, cuya obra describe, de manera bastante singular, la sublimación contemporánea. Se podría decir que el trabajo de este autor constituye un mapa del mundo civilizado moderno. Sus imágenes, a la vez que impresionantes, resultan inquietantes. $Y$ ante esto cabe preguntarse: ¿cuál es el origen de esta reacción? En este sentido es muy revelador el pensamiento del escritor irlandés Edmund Burke, quien en 1757 publicó A Philosophical Inquiry into the Origin of our Ideas of the Sublime and Beautiful (una investigación filosófica sobre el origen de nuestras ideas acerca de lo sublime y lo hermoso). Este trabajo fue de gran influencia para esteticistas y otros filósofos, destacando entre ellos al prusiano Inmanuel Kant. Tal es la importancia del pensamiento teórico de Burke, que en su tratado, mencionado anteriormente, establece la primera definición moderna de lo sublime: "Aquello que es de algún modo terrible, o tiene que ver con los objetos terribles, o actúa de una manera análoga al terror, es una fuente de lo sublime. Es decir, se trata de la producción de la emoción más fuerte que la mente es capaz de sentir" (cit. en Ohlin, 2002, p. 23). Las fotografías de Andreas Gursky podrían interpretarse como analogías del sobrecogedor mundo global e hieratizado que nos acontece. Su obra constituye un mapa del mundo civilizado postmoderno, cuya mecánica y sistematización se vuelve en ocasiones escalofriante.

En el planteamiento teórico de Andreas Gursky, la dinámica vertiginosa de la globalización constituye el lugar actual de lo sublime. Este dinamismo global hace referencia al gran sentimiento de insignificancia que define nuestra presencia en el paisaje. En términos de Burke se podría decir que estamos "aniquilados". En base a esta actitud, Gursky pretende invocar lo sublime a través de sus imágenes. El fotógrafo manipula sus fotografías con total libertad, alterando la arquitectura de los edificios y entornos naturales. Este proceso de trabajo da lugar a la repetición de patrones formales, abordando la profundidad cromática, y generando imágenes que reflejan el tiempo detenido. En este comportamiento artístico se revela una corre- spondencia crucial con el sentido de lo sublime (Ohlin, 2002). Las fotografías de Gursky denotan estructuras visuales universales que definen nuestro paisaje antrópico, y que devienen en un espíritu romántico de nuestra existencia. El enfoque compositivo y conceptual de las imágenes de Gursky refleja el comportamiento social contemporáneo, caracterizado por el individualismo del ser humano en medio de un vacío existencial. Además, la riqueza y la proporción cinematográfica de los paisajes panorámicos de Jeff Wall en la década de los 80 , concebidos como mapas del poder económico y social, pueden haber influido en la obra de Gursky, en cuyas fotografías también se escribe la historia global del presente. Sus paradigmas se basan en la transgresión deliberada del horizonte perceptivo eurocentrista por la pluralidad global de contextos de experiencia vividos y la existencia de sociedades paralelas (Beil y Fessel, 2008). En su obra Kairo, Diptych (El Cairo, díptico), pareciera que el tiempo se dilata, insinuándose posibles argumentos relacionados con algún drama humano que requiere nuestra atención. Así pues, desde una perspectiva social, y frente a la contemplación de la obra a la que nos hemos referido, podríamos plantear la siguiente reflexión: ¿qué tipo de ciudad es esta, qué tipo de sistema, y qué produce tal caos? (Gursky, Bradley, Hilty y Biggs, 1995).

Profundizando en la teoría de lo sublime, resulta también apropiado hacer referencia a las ideas sobre el tema expuestas por Inmanuel Kant en 1764. En su publicación Observations on the Feeling of the Beautiful and the Sublime (observaciones sobre el sentimiento de la belleza y lo sublime), Kant realiza sus aportaciones abordando la caracterización de ambos conceptos, haciendo distinción entre ellos, e incitándonos a reflexionar sobre el poder de lo sublime y lo bello en la naturaleza humana. Por otro lado, tomemos en consideración el pensamiento del crítico de arte y teórico John Ruskin, quien en vez de separar los conceptos de belleza y sublime como hizo Burke, considera que lo sublime es el grado más alto de belleza. Además, la teoría de Ruskin influyó, entre otros, en el pintor británico Joseph Mallord William Turner, cuyo discurso plástico entra en consonancia con la concepción sublime de la fotografía actual de paisaje.

El fotógrafo alemán Elger Esser, durante un viaje a Francia en 1996, descubrió que el paisaje sería el tema central de su fotografía. También se inscribe en lo sublime y lo romántico, y la luz es un elemento esencial de su lenguaje, que interviene trascendentalmente en la connotación plástica de sus imágenes. Otro aspecto 
crucial de sus fotografías es la melancolía que se impone involuntariamente. Además, en sus obras más recientes, basadas en tarjetas postales, se adquiere un alto grado de abstracción. ${ }^{2}$ Asimismo cabe señalar la fotografía Salcombe Sands, Devon, 23rd May (arenas de Salcombe, Devon, 23 de mayo), de 2008, del artista Simon Roberts, cuyo trabajo perteneciente a su serie denominada We English, expresa la belleza de lo mundano y lo banal, explorando la relación establecida entre el ser humano y su entorno.

Como vemos, se puede observar en un periodo reciente y en su corriente artística una actualización del romanticismo, y otro ejemplo visible nos lo da Kim Keever a través de su obra. La imagen Summer: Blue, Yellow and Gray (el verano: azul, amarillo y gris), conecta con esa atmósfera sublime del romanticismo, y conceptualmente con la Hudson River School. El principal discurso de su obra atiende a una profunda veneración de las fuerzas naturales. Además, la luminosidad cromática de sus imágenes nos sugiere un universo de transformaciones plásticas que podrían estar advirtiéndonos de circunstancias catastróficas relacionadas con el efecto de la humanidad sobre la tierra. No obstante, la intención del artista es presentar la belleza del paisaje en sí misma, sin referencias al hombre y a la industria, creando un imaginario propio más allá de las horas y los días. La fotografía de Kim Keever Summer: Blue, Yellow and Gray formó parte de una exposición colectiva titulada Trouble in Paradise. Examining Discord between Nature and Society (problemas en el paraíso. Examinando la discordia entre la naturaleza y la sociedad), que tuvo lugar en el Tucson Museum of Art, en Tucson, Arizona, entre el 28 de febrero y el 28 de junio de 2009. Los artistas incluidos en esta muestra presentan ideas filosóficas, ecológicas y de naturaleza política y, así pues, se configura un discurso sobre el impacto de la humanidad en el paisaje. Esas obras significan la contemplación de nuestra existencia en el mundo moderno (Sasse y Handlin, 2009). Estos artistas plantean cómo la discordancia medioambiental es empaquetada y entregada a nosotros a través de los mass media. Las nubes de humo, los paisajes devastados, las inundaciones o la bomba atómica se han convertido en símbolos que reconocemos inmediatamente por el frecuente bombardeo mediático.

El romanticismo aparece también implícito en las fotografías de Yannick Demmerle. En su obra Untitled (\#6) (sin título no6) de la serie Les Nuits Étranges (noches extrañas), se detecta una importante nota de lo sublime, la curiosa mezcla de asombro y terror que muchos artistas románticos captaron en la naturaleza y transmitieron con sus pinturas (Earle, Phillips, Squiers y Wallis, 2006). La idea de la contemplación tranquila frente al mundo natural como un lugar por descubrir se explicita en el trabajo de Yannick Demmerle, aunque lo sublime en sus paisajes genera además una sensación de inquietud en los pantanos y espacios forestales que fotografía. Subyace una perturbación oculta en las imágenes del artista, que se intensifica por la cercanía extrema de la naturaleza fotografiada.

Esta exploración del mundo natural, conectando física y emocionalmente con el entorno de forma muy cercana, es una actitud que aborda la fotógrafa estadounidense Dana Fritz. A través de su proyecto Views Removed (figs. 1 y 2), comenzado en 2012, Fritz se plantea el hecho de que la imagen actúa como un plano frente al cual podemos desarrollar una íntima contemplación del mundo natural. Ella nos propone la contemplación espiritual a través de sus imágenes, y así lo afirmaba en una conversación mantenida con la artista en noviembre de 2012, en Lincoln, Nebraska. Dana Fritz asegura su interés por propiciar a través de sus fotografías una experiencia perceptiva y cognoscitiva del paisaje que trasciende los límites objetivos de la realidad para introducirnos en un estado de conciencia espiritual en torno a la naturaleza. A la artista le interesa comprender qué tipo de naturaleza queremos, objetivo que persigue e indaga con su trabajo. Se podría apuntar incluso que el desarrollo de esta cuestión resulta clave para ella, y que la búsqueda de la respuesta la lleva a explorar una vía más experimental. De este modo, aborda con solidez el concepto de invención de un nuevo paisaje, mediante el montaje de varias imágenes en su proceso de trabajo, utilizando métodos analógicos de revelado. Deja, por tanto, a un lado la fotografía puramente directa con la que había trabajado hasta el momento para adentrarse en la aventura de crear nuevos horizontes espaciales. Es importante resaltar cómo el protagonismo de la naturaleza en la obra de Dana Fritz parece imponerse frente al dominio imperante de las construcciones del individuo en el espacio, por lo que resulta además de gran interés destacar su serie Terraria Gigantica, realizada entre 2007 y 2011 (fig. 3), con la que expone un diálogo entre artificio y verdad, fotografiando e investigando tres de las construcciones paisajísticas interiores más grandes del mundo: Biosphere 2, a las afueras de Tucson, Arizona; Lied Jungle y Desert Dome en el zoológico Henry Doorly, en Omaha, Nebraska; y el Proyecto Eden en Cornualles, Inglaterra (Ruud, 2013). 
Figura 1. Dana Fritz. Mountain Forest, de la serie Views Removed. 2014. Gelatin silver print.

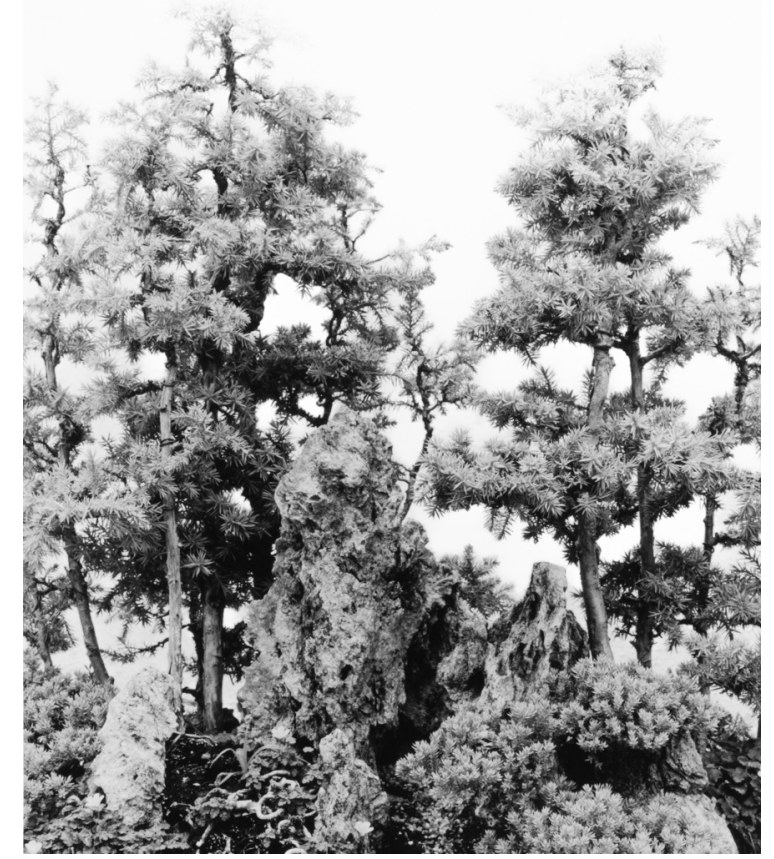

Fuente: (c) Dana Fritz, cortesía de la artista.
Figura 2. Dana Fritz. Momiji, de la serie Views Removed. 2014. Gelatin silver print.
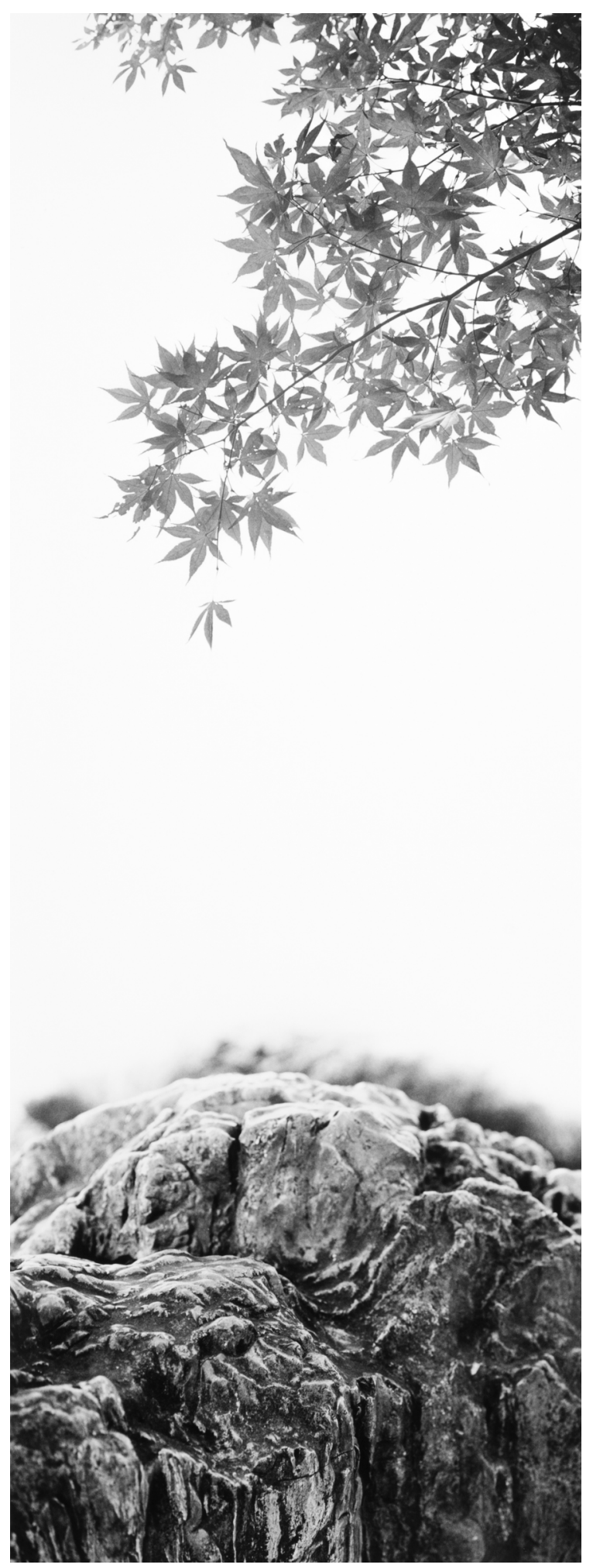

Fuente: ( Dana Fritz, cortesía de la artista. 
Figura 3. Dana Fritz. Rain Forest Mist, Biosphere 2, de la serie Terraria Gigantica. 2007. Archival pigment print.

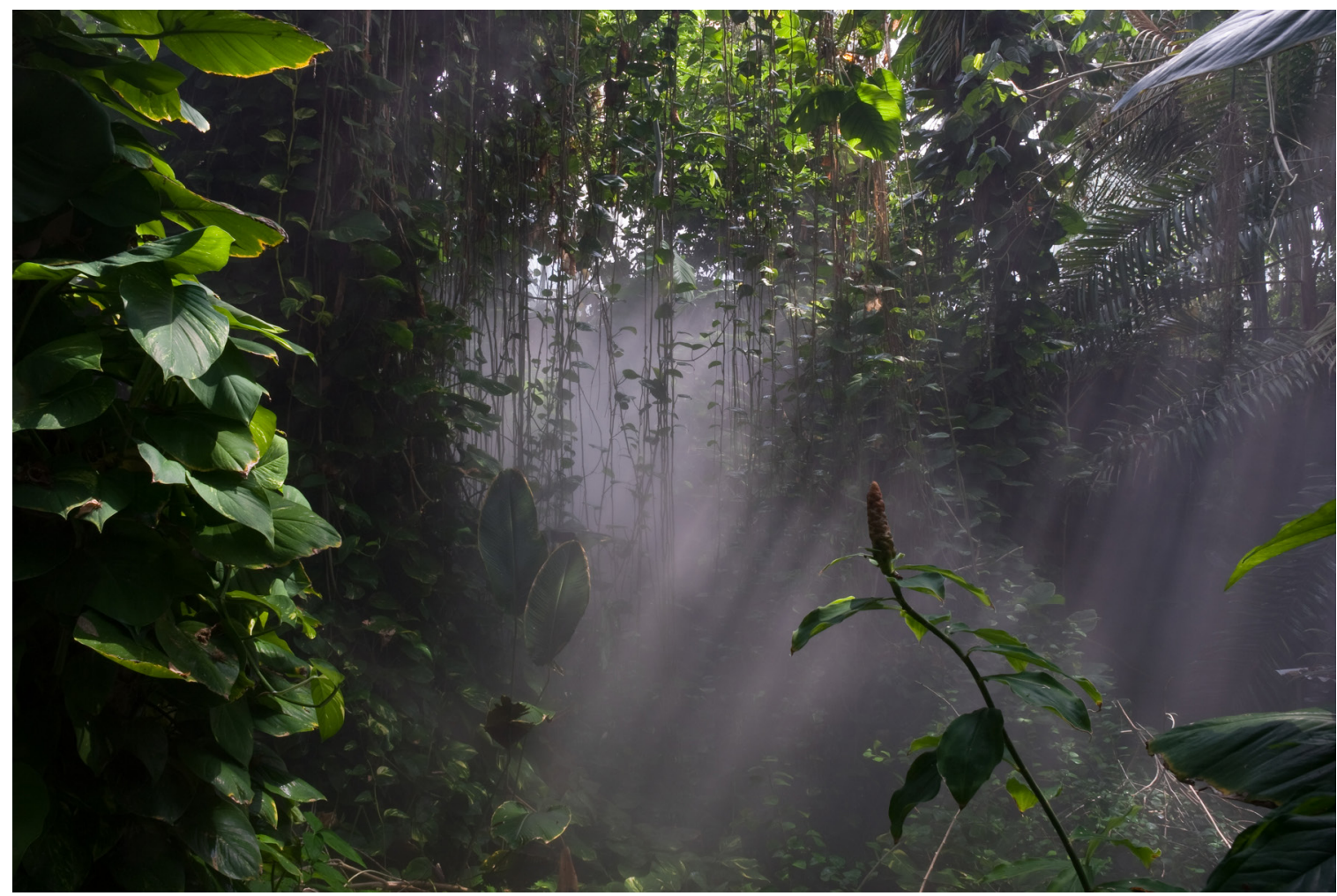

Fuente: (c) Dana Fritz, cortesía de la artista.

La condición romántica de la naturaleza es advertida también en la obra del fotógrafo alemán Axel Hütte. Este artista conecta lo sublime con la abstracción perceptiva de sus paisajes, y emplea las variaciones de la luz y su comportamiento sobre los diversos elementos para crear composiciones prácticamente abstractas. Es de destacar que a finales de los años 80 , retoma el tema tradicional del paisaje romántico, viajando por diversos países con el objetivo de reflejar la idea de lo sublime como punto de partida en su proyecto fotográfico (Pratesi y Carpi de Resmini, 2009). El interés de este autor por el paisaje fue incrementando, sobre todo, durante la década de 1990. A partir de este momento, tratará con predilección escenas de ciudad (estaciones de metro, trenes subterráneos, entradas a edificios, etc.). Incidiendo en un paisaje desarrollado, símbolo del romanticismo, Hütte incorpora a sus imágenes fragmentos de arquitectura, creando un tipo de marco geométrico en sus fotografías. Al mismo tiempo, sus imágenes poseen un tipo de belleza natural ambigua, una estética dispuesta por los humanos y orientada por el consumo. Aunque las imágenes de Hütte no son críticas directas al paisa- je industrial, estas, manifiestan que lo que parece ser virgen en realidad solo está temporalmente libre de la influencia humana ${ }^{3}$. Hablamos de fotografías que nos inducen a reflexionar sobre la propia existencia.

Hay que tomar conciencia de que para muchos artistas fotografiar el paisaje implica proyectar valores intangibles que describen nuestra existencia. El fotógrafo japonés Hiroshi Sugimoto explora el tiempo, el empirismo o la metafísica, proponiéndonos una nueva ventana al mundo cargada de sublimación y energía inmaterial. Su serie Seascapes expresa la naturaleza de forma documental y metafísica al mismo tiempo, es una exploración de la barrera entre lo físico y lo inmaterial. Conceptos como el tiempo y el espacio, indagados en sus fotografías, amplían nuestra percepción de la naturaleza, incitándonos a reflexionar sobre el origen e historia del mundo y de nuestra cultura. Sugimoto nos propone una percepción ampliada del tiempo y el espacio, en la que lo dramático y lo enigmático versan hacia una nueva revelación espiritual sobre la que interpretar lo sublime en la actualidad. Las siguientes palabras del artista, explicitan su compromiso con la espiritualidad: 
"Yo decidí ser espiritual y mantener una actitud igual con respecto a todas las religiones. La cuestión más importante es de dónde vienen la religión y la espiritualidad. Nuestro estadio de conciencia humana empezó con el desarrollo del sentido del tiempo y de la consciencia, lo cual está acompañado por un impacto religioso. Por lo tanto, todo está relacionado, y también lo está con mis paisajes marinos. Reflexionar sobre el pensamiento religioso... ¿Por qué, cuando contemplas la naturaleza o los paisajes marinos, sientes que algo te trae a la memoria tus viejos recuerdos, ya sean personales o de la humanidad?"4

La inquietante armonía destilada en muchas de sus fotografías de paisajes marinos puede propiciar dramas humanos en nuestra memoria, una hibridación de sentimientos que marca nuestra existencia. Esta sensación nos lleva a valorar la experiencia de lo sublime como un estado de transformación espiritual, de fuerzas encontradas. La lógica espacio-temporal de sus obras parece reflejar lo inmaterial, que subyace más allá del tiempo y el espacio. Esta idea se proyecta con hervor en su serie Theatres, con la que nos habla de la presencia humana, ya que estas obras, realizadas con una exposición larga, han acumulado la información de los millones de fotografías que integran una película. Por tanto, la aglutinación de fotogramas proyectados en una línea temporal concreta, traduce la información inmaterial acumulada en un plano blanco sobrio y enigmático que propicia un estado de contemplación ultrasensorial.

El estado contemplativo en el que nos introduce Sugimoto lo experimentamos también al percibir las fotografías de la artista estadounidense Lynn Davis, quien a través de su obra desarrolla un camino espiritual propio. El equilibrio y la armonía se instauran en el seno de su trabajo, centrado en el paisaje, y que incluye series como Water o Ice. La fotógrafa Lynn Davis, interesada en lo efímero y lo cambiante, proyecta una mirada escultórica y un enfoque minimalista en gran parte de su obra. En su serie Ice se registra la belleza sublime de los icebergs, reflejándose un mundo onírico en el que lo abrupto y lo pacífico convergen. Estos icebergs son construcciones escultóricas abstractas de naturaleza efímera que interactúan con su entorno y que simbolizan el proceso de deconstrucción y disolución que está experimentando nuestro planeta. El interés por documentar la realidad cambiante lleva a Davis a viajar a Irán en 2001 con la intención de buscar material para su serie Persia Antigua. La artista exploró los espacios desérticos y fotografió arquitecturas preislámicas y paisajes casi lunares, revelando en ocasiones la frágil relación entre la naturaleza y la civilización.

\section{LO SUBLIME INDUSTRIAL}

El paisaje industrial nos proporciona una doble vertiente interpretativa, pues integra en su fuero los conceptos de poder y belleza. Dichos conceptos coexisten en la cuadratura discursiva de la fotografía, destacándose un carácter de relación sugerente entre la crítica y la estética del paisaje. Cabe señalar que las fotografías del artista canadiense Edward Burtynsky nos aproximan al paisaje manufacturado del contexto actual, pues sus obras poseen un incitante vínculo entre lo bello y lo degradante, y nos hablan de las fuerzas de poder que articulan las empresas industriales.

Edward Burtynsky se expresa con un vocabulario romántico, y lo sublime será un concepto tradicional del paisaje que proyectará en su obra. Edmund Burke, en su tratado A Philosophical Enquiry into the Origin of our Ideas of the Sublime and Beautiful (una investigación filosófica sobre el origen de nuestras ideas acerca de lo sublime y lo hermoso), afirmó que lo sublime evocaba el sentimiento de ansiedad frente a la naturaleza, un estimulante reconocimiento de sus ilimitados poderes sobre la humanidad. Sin embargo, Burtynsky en ocasiones traza su experiencia de lo "sublime aterrador", basándose en el mundo del orden más que en las fuerzas de lo salvaje. Sus imágenes provocan un aplastante shock, producido por el artificio de la máquina y su poder para organizar y transformar el espacio, disociado en todo momento de la fuerza espiritual o religiosa del paisaje. El concepto de lo sublime ha sido transformado. Este hecho se manifiesta tomando conciencia de todos aquellos elementos que se han introducido en la vida del hombre desde la era industrial, modificando su relación con el entorno: la máquina, la luz eléctrica, el motor de combustión, el río, la presa, la ciudad, la fábrica, el avión o el coche. Se produce, por tanto, una variación de lo sublime, como síntoma de la ciencia, la mecanización y el progreso (Mitchel y Rees, 2009).

Cabe señalar la exposición de Edward Burtynsky titulada The Industrial Sublime (lo sublime industrial), que tuvo lugar en 2012 en el Frist Center for the Visual Arts, en Tennessee, y cuya temática está siendo explorada por numerosos artistas consagrados a la fotografía de paisaje en la actualidad. Nuestro sistema de extracción, producción y manufactura instila el miedo de que hemos creado algo más poderoso que la fuerza humana, que podría acabar con nosotros si continuamos usando nuestro poder con el único propósito de conducir económicamente nuestra sociedad eludiendo el factor ecológico. En la obra de Burtynsky, lo sublime instiga al terror, 
transmitiéndonos un desasosiego constante sobre la relación del ser humano con su entorno y la industrialización imparable que acontece.

Es importante señalar la ineludible conexión que existe entre las fotografías del artista americano John Pfahl y el discurso de Edward Burtynsky. Ambos posicionamientos artísticos implican una caracterización sublime del paisaje. John Pfahl, quien conjuga el poder industrial con la búsqueda de la belleza a lo largo de todo su trabajo, llevó a cabo el proyecto Altered Landscapes (paisajes alterados), y a través del mismo fundamenta su pensamiento artístico. La exploración fotográfica de la alteración del paisaje es una actitud artística que tienen en común Pfahl y Burtynsky, y en este sentido resulta necesario desarrollar una aproximación reflexiva en torno al trabajo de John Pfahl.

El citado artista americano, con su serie Power Places (lugares de energía), sugiere representaciones de plantas de energía nuclear realizadas al principio de la década de 1980 y plantea interrogantes necesarios para hallar la compleja estructura del mundo. Ya desde los inicios del siglo XIX y a raíz del ferrocarril y la industria, los estadounidenses se han cuestionado la intrusión de la tecnología en relación al medioambiente. Por tanto, cabe considerar el planteamiento artístico de Pfahl quien, consciente de los peligros que suponen las centrales nucleares o cualquier otra tecnología de producción de energía, proyecta sus paisajes con cierta ironía, aunque parezca remitirnos a una actitud de condena. Así pues, sus imágenes expresan una sugestiva conjunción entre el poder del lugar y su belleza (Jussim, 1990). Su portafolio Power Places ha sido revisado por numerosos críticos, quienes se muestran algo confusos sobre los motivos del artista en la creación de tales imágenes. Las fotografías de John Pfahl expresan colectivamente una nostalgia romántica inscrita en la modernidad, en la que las plantas de energía, así como las formaciones de las rocas y los árboles se perciben como un nuevo tipo de belleza ingenieril. Destaquemos su obra Three Mile Island Nuclear Plant, Susquehanna River, Pennsylvania (planta de energía nuclear Three mile island, río Susquehanna, Pensilvania), de 1982, perteneciente a su serie Power Places, en la que se expresa la coexistencia de lo natural y lo industrial. A partir de sus fotografías, se aprecian además otras lecturas que nos advierten sobre el carácter natural y necesario de la utilización de la energía, hallada en todo el paisaje (Bright, 1985). Sus imágenes poseen un carácter ambivalente, que nos confiere una posición crítica neutral. El propio artista expresa una actitud de lo más imparcial:
"No estoy interesado en lanzar simples opiniones o hacer declaraciones propagandísticas. Me parece que cuando más de un mensaje se presenta en una obra de arte, se crea una tensión que pide a gritos ser resuelta. Las personas condicionadas por la fotografía publicitaria y sobre todo por el fotoperiodismo esperan un mensaje inequívoco y encuentran mi trabajo desconcertante. Sin embargo, espero que la mayoría de los espectadores sean provocados por la tensión fomentada deliberadamente a pensar más profundamente sobre la complejidad de las cosas. La intención es hacer que las personas se vinculen con las implicaciones de una imagen" (cit. en Jussim, 1990, p. 15) . $^{5}$

En el mundo actual, tan congestionado de imágenes, es necesario detenernos y reflexionar, analizando conceptos universales como la belleza, instaurados en nuestra existencia y llenos de significado. En ocasiones, el concepto de belleza es asociado a un terror exponencial, como ocurre al examinar las imágenes de John Pfahl. En su obra Rancho Seco Nuclear Plant, Sacramento, California (central nuclear Rancho Seco, Sacramento, California) puede apreciarse esta idea pues, aunque no es nueva en el arte, el tratamiento del tema sin duda es diferente. Su obra evoca la primera línea de un poema de Rainer Maria Rilke: "La belleza es solo el principio del terror..." (cit. en Jussim 1990, pp. 15-16) $)^{6}$.

Del fotógrafo John Pfahl también merece una consideración importante su serie Smoke (humo), cuyo motor discursivo está fundamentado en los graves peligros medioambientales sufridos en las últimas décadas. Sus paisajes, vestidos por una estética atrayente, sugieren a su vez una sugestiva interpretación en relación a la alarmante realidad inscrita en la literatura de sus imágenes (Jussim, 1990). Ciertamente, las fotografías de nubes, abstractas y evocadoras, que Alfred Stieglitz aborda en su serie Equivalents (equivalentes), pueden vincularse con la serie Smoke de Pfahl. El texto mostrado a continuación refleja la experiencia del artista John Pfahl al abordar este proyecto fotográfico:

"La prodigiosa pantalla de humo que brota de las pilas de coque de la corporación Bethlehem Steel, en Lackawanna, Nueva York, desde donde mejor se puede ver es desde un acantilado de escoria mirando la planta desde el norte. Un estrecho canal de barco de aguas oscuras me separa de los edificios de la fábrica, silueteados y bañados en el resplandor del lago Erie. Por el simple acto de mirar a través del enorme teleobjetivo de mi Hasselblad, me adentré en una fantasmagoría de luz y color. Atraído y con repulsión a la vez, me siento envuelto en un espectáculo de la 
naturaleza verdaderamente asombroso. Es como si de repente me precipitara en una catarata rugiente, un volcán en erupción, o una tormenta violenta en el mar. Silbatos de alarma soplan y el humo se descarga en el cielo. Las formas se expanden y cambian mucho más rápido de lo que habría imaginado, y en su cenit absoluto, se disipa en el aire antes de que pueda tomar otro respiro.

La presentación tiene sus propios ritmos y lógica como los géiseres, pasa de quince a veinte minutos antes de que se produzca otra descarga. Sin duda, la eficiencia de los mecanismos internos de la fábrica dicta una lógica de los tiempos, pero desde mi punto de vista distante yo sólo puedo verlos como parte de un proceso irracional, aterrador en su veleidad. Las oscuras emisiones de humo, chocan con nubes blancas brillantes, ambas arrastradas en un momento por un denso vapor amarillo. Yo giro mi cámara sobre el trípode rápidamente, moviendo el objetivo de un vórtice a otro, intentando seguir el ritmo de las rápidas transformaciones.

\section{$[\ldots]$}

A medida que las horas pasan y el sol disminuye, rosas y naranjas destacan atrás por su brillo conectando con las imponentes nubes de efluvio. Cada hora, cada día, cada momento del año aguarda sus propias sorpresas" (cit. en Jussim, 1990) ${ }^{7}$.

John Pfahl describe su experiencia como un verdadero hallazgo, que en ocasiones lo llevará a enfrentarse a los fardos de oscuras nubes que se desplazan hacia él, quedando sumergido en una atmósfera tóxica. Dicha situación nos podría estar hablando de la cotidianeidad de lo dañino, ya que el olor a humo se convierte en un aroma familiar del que apenas se llega a ser consciente. De hecho, regularmente asumimos un ambiente de toxicidad que define nuestro paisaje.

Pfahl suele presentar la arquitectura de la industria nuclear del siglo XX con el lenguaje romántico de la pintura del s. XIX. El romanticismo, implícito en las fotografías industriales de Pfahl y Burtynsky, nos permite concebir una solidez conceptual y narrativa en sus trabajos. El crítico John Bentley Mays relacionó las fotografías de Burtynsky con el paisaje industrial sublime, un tipo de imagen característica de Europa, y especialmente de Gran Bretaña, durante el siglo XVIII. El principal historiador en este género, Francis Klingender, escribió:

"Las ilustraciones de temas industriales fueron creciendo progresivamente durante la segunda mitad del siglo XVIII. Pozos de carbón en brezales remotos, canteras cavernosas en las montañas, molinos a la orilla de los arroyos y, sobre todo, las obras de hierro en sus hornos de cal, provocaron un llamamiento en aquellos que buscaban lo pintoresco como ejemplos perfectos de lo sublime" (Klingender, 1947, p. 66).

Los numerosos proyectos de John Pfahl, Altered Landscapes (paisajes alterados), Picture Windows (ventanales), Video Landscapes (vídeo paisajes), Submerged Petroglyphs (petroglifos sumergidos), Power Places (lugares de energía), Missile/Glyphs (misiles/glifos), Arcadia Revisited (Ia arcadia revisitada) o Smoke (humo), entre otros, expresan un proceso continuo de ideas en relación a la naturaleza y los efectos de la intervención humana en ella (Jussim, 1990). Es destacable cómo el poder destructor de los procesos industriales, con frecuencia, provoca una paradójica belleza en la atmósfera del paisaje. Se produce un romanticismo cromático, percibido tanto en el aire como en el agua, que nos incita a valorar el proceso de degradación que acecha a muchos ríos y minas del planeta.

En relación a lo anterior, son bastante significativos también los proyectos Tailings (escombros) y Australian Minescapes, del artista Edward Burtynsky. Su serie Tailings está formada por un grupo de fotografías de escombros de níquel, cerca de la ciudad de Subdury, situada en la provincia de Ontario, en Canadá. Los intensos naranjas y rojos, causados por la oxidación del hierro y por la mezcla de diferentes metales desechados, nos transmiten la idea de desastre natural provocado por el poder destructor de las industrias, que desechan residuos que acaban en los ríos y lagos. Este es un proceso del que a veces parece que no somos del todo conscientes, o ¿se podría pensar que no queremos serlo? A menudo, ciertos intereses económicos o políticos nos alejan de la verdadera realidad humana, para hacernos partícipes de la gran máquina colectiva que constituye el sistema social al que pertenecemos. Las conciencias de los individuos son sometidas colectivamente por los intereses industriales, un proceso cada vez más difícil de controlar y frenar, debido a la colosal infraestructura técnica y económica que rige la compleja construcción del paisaje.

Estamos asistiendo a una continua renovación física e intelectual del entorno, en la que todos somos partícipes, y por lo tanto también somos responsables de los resultados que se obtengan. En cualquier caso, las fotografías de Edward Burtynsky amplían enormemente nuestra sensibilidad estética y social respecto al entorno que nos ocupa. El poder y la belleza de sus imágenes nos conducen a investigar el sistema huma- 
no que interviene en la imparable modificación del paisaje actual, contribuyendo consecuentemente a la axiomática fragilidad de la naturaleza. El propio Edward Burtynsky, expresa:

"Si la experiencia humana puede considerarse como una manifestación de los sueños y los deseos, las minas pueden ser consideradas como el origen de la materia prima de esa experiencia. En un nivel de entendimiento el mineral rico es manufacturado en los objetos de nuestros deseos colectivos: los automóviles que conducimos, las televisiones que vemos, los aviones que vuelan alrededor del mundo, las casas que nos proporcionan refugio y consuelo, y un sinfín de aparatos y productos. Si el oro, la plata y los diamantes son los objetos de valor que nosotros conferimos para honrar a grandes ciudadanos y profesar nuestro amor, entonces ¿no son los grandes huecos que dejamos en ese paisaje residual un testamento duradero de estas ambiciones? Las imágenes derivadas de esos paisajes llegan a ser simbólicas. Lo que esta civilización deja es la creación involuntaria de gigantescos movimientos para nuestra forma de vida" (cit. en Mitchell, 2009) ${ }^{8}$.

La existencia humana está condicionada por nuestras acciones y, de acuerdo a cómo dirijamos nuestra relación con el medio, ya sea este natural o urbano, estaremos contribuyendo a la consolidación o degradación del paisaje social colectivo. Las claves para analizar la evolución de dicho paisaje están implícitas en la obra de Burtynsky, cuya vocación como fotógrafo de paisaje se remonta algunas décadas atrás en el tiempo, cuando con apenas veinte años observó las fotografías de Carleton E. Watkins en el Metropolitan Museum of Art, un hecho que fue realmente determinante en la trayectoria de su trabajo. Watkins destacó no solo como fotógrafo de vistas sublimes del parque Yosemite y la costa del Pacífico, sino que además dominó el arte de fotografiar las intervenciones del hombre en el paisaje: los ferrocarriles, los trabajos de hierro, los almacenes de madera, las presas y las minas. Este artista californiano fotografió con el mismo interés tanto lo natural como lo sublime de la industria. Una de sus fotografías más características y reconocidas es Cape Horn near Celilo (Cabo de Hornos cerca de Celilo), de 1867. En 1871, Carleton E. Watkins, realizó con placas de mamuts una serie de fotografías de las minas de grava de North Bloomfield, en el condado de Nevada, en California. Además, fotografió las tuberías usadas en las minerías de oro hidráulicas de la misma región. Una de sus obras al respecto es Malakoff Diggins, North Bloomfield, Nevada (Pauli, 2003).
Según expresa el propio Edward Burtynsky: "Recuerdo la primera vez que vi impresiones de Carleton E. Watkins en el Museo Metropolitano de Nueva York a principios de los 80 . Sus fotografías eran destacables, con una vitalidad en las imágenes que es difícil encontrar en trabajos contemporáneos" (cit. en Pauli, 2003) ${ }^{9}$. Burtynsky quería seguir el camino de Watkins, aunque adaptándose a su generación. Decidió que lo realmente relevante para nuestra época eran aquellas imágenes que mostraban cómo hemos cambiado el paisaje, yendo por el camino contrario a la persecución del progreso (Pauli, 2003).

En este sentido resulta conveniente considerar el planteamiento artístico del fotógrafo australiano Chris Round, cuyo discurso, centrado en los intereses y preocupaciones de las últimas décadas, expresa entre otras cosas la fragilidad de la naturaleza. Existe una conexión conceptual entre su obra y las fotografías de Edward Burtynsky. De hecho, el contenido argumental del artista Chris Round muestra un especial interés por los paisajes influenciados por el hombre, por la concepción post-natural del entorno. El artista australiano encuentra esos espacios dinámicos y excitantes, llenos de energía y poder, al estar en constante flujo y cambio. Por consiguiente, el ser humano cambia constantemente su relación con el medio. Este es un hecho sobre el que debemos reflexionar. En el trabajo de este autor se revelan los conceptos de poder y belleza, un paralelismo de valores positivos y negativos que confluyen hacia el resultado plástico de sus fotografías. Destaca su proyecto Beauty and the Beast. Industrial Landscapes of Australia (La bella y la bestia. Paisajes industriales de Australia).

Reflexionando en consecuencia, actualmente el paisaje se ha convertido en una compleja estructura de pensamiento. Existe cierta ambigüedad en la proyección semántica del entorno que estamos modificando. Por lo que estos paisajes analizados podrían concebirse como desafíos o metáforas visuales enfrentadas. Cabría preguntarse entonces qué efecto tienen las plantas de energía en su medioambiente o qué lugar ocupa lo sublime en la fotografía contemporánea. En la exploración del desierto contemporáneo que realiza Richard Misrach con sus fotografías, él encuentra una belleza irónica en los cráteres de bombas y los esqueletos de animales. Existe aquí un vínculo directo entre la estética y la política (Foresta, Gould y Marling, 1992). En 1979 Misrach comenzaría su expansivo proyecto fotográfico, registrando la destrucción del paisaje del desierto. Además, a diferencia de Ansel Adams y William Henry Jackson, Misrach no buscó los lugares más visitados o de concepción más sublime, sino que indagó en las zo- 
nas más tranquilas y menos conocidas del sureste de California, el noroeste de Utah y Nevada (Ruud, 2013).

Mediante la actitud artística de Richard Misrach, advertimos por tanto cómo el autor adopta otra manera de afrontar la naturaleza con la cámara. Resulta pues necesario comprender que, en la actualidad, el concepto de belleza ha sido transformado, paralelamente a la modificación del paisaje, lo que de manera inmediata nos introduce en una reconsideración de la gestión social del entorno y del tipo de naturaleza que estamos construyendo. Podemos percibir belleza en un río contaminado, algo que nos genera a la vez desasosiego. Se podría decir que percibimos lo bello en un estado de alarma permanente, inmersos en un escenario de espacios afectados por la industrialización. Existe, por tanto, una implicación emocional más allá de la armonía cromática de la imagen, que nos lleva a cuestionar cómo estamos transformando el entorno.

Si nos trasladamos al 29 de noviembre de 1979 e indagamos en las palabras del fotógrafo Ansel Adams, comprenderemos cómo ha evolucionado el concepto de belleza. A continuación, se muestra un breve extracto de su discurso, que pronunció en el John Hancock Hall del Photography Resource Center, en Boston, bajo el título My Life in Photography (mi vida en la fotografía):

"Sentir y expresar la asombrosa belleza de las cosas--la tierra, la piedra y el agua, la bestia, el hombre y la mujer, el sol, la luna y las estrellas--

La sangre--la explosiva belleza de la naturaleza humana, de sus pensamientos, delirios y pasiones. $Y$ en la naturaleza humana su realidad elevándose... para sentir y comprender verdaderamente la belleza natural, es la única negociación de la poesía.

Distensión... ¡Mucha gente de hoy en día siente realmente miedo de la belleza!"10.

En el contexto actual, las marcas que alteran el paisaje nos conducen hacia otra mirada de la belleza y de lo sublime. El fotógrafo Roderik Henderson reflexiona sobre esta idea y escoge las geografías desérticas (al igual que Richard Misrach) para desarrollar su obra. Henderson viajó durante años por los desiertos de Nevada, California, Utah, Nuevo México, Arizona y el oeste de Texas, en busca de la "nada" absoluta, de la naturaleza intocable del desierto, y descubrió que esos lugares estaban llenos de huellas de la actividad humana. Destaca su serie Badlands (tierras yermas), cuyas fotografías reflejan los desiertos de alrededor de Caineville, Utah, una de las áreas más desoladas del mundo. La extrema topografía de este paisaje y sus colinas abruptamente erosionadas lo convierten en un lugar popular para motociclistas y vehículos todoterreno. Según algunos estudios realizados, la tierra se ha erosionado a un ritmo del $300 \%$ más rápido por las motos y los vehículos todoterreno. En la imagen Badland \#14, de 2001 (fig. 4) de Roderik Henderson, los rastros de los neumáticos provocan cicatrices en la tierra, agrediendo los suaves contornos del paisaje desértico. Además, el carácter dramático de la tormenta de nubes de la imagen en blanco y negro condiciona nuestra percepción de lo sublime en dicha obra (Sasse y Handlin, 2009).

Figura 4. Roderik Henderson. Badland \#14. 2001. Gelatin silver print.

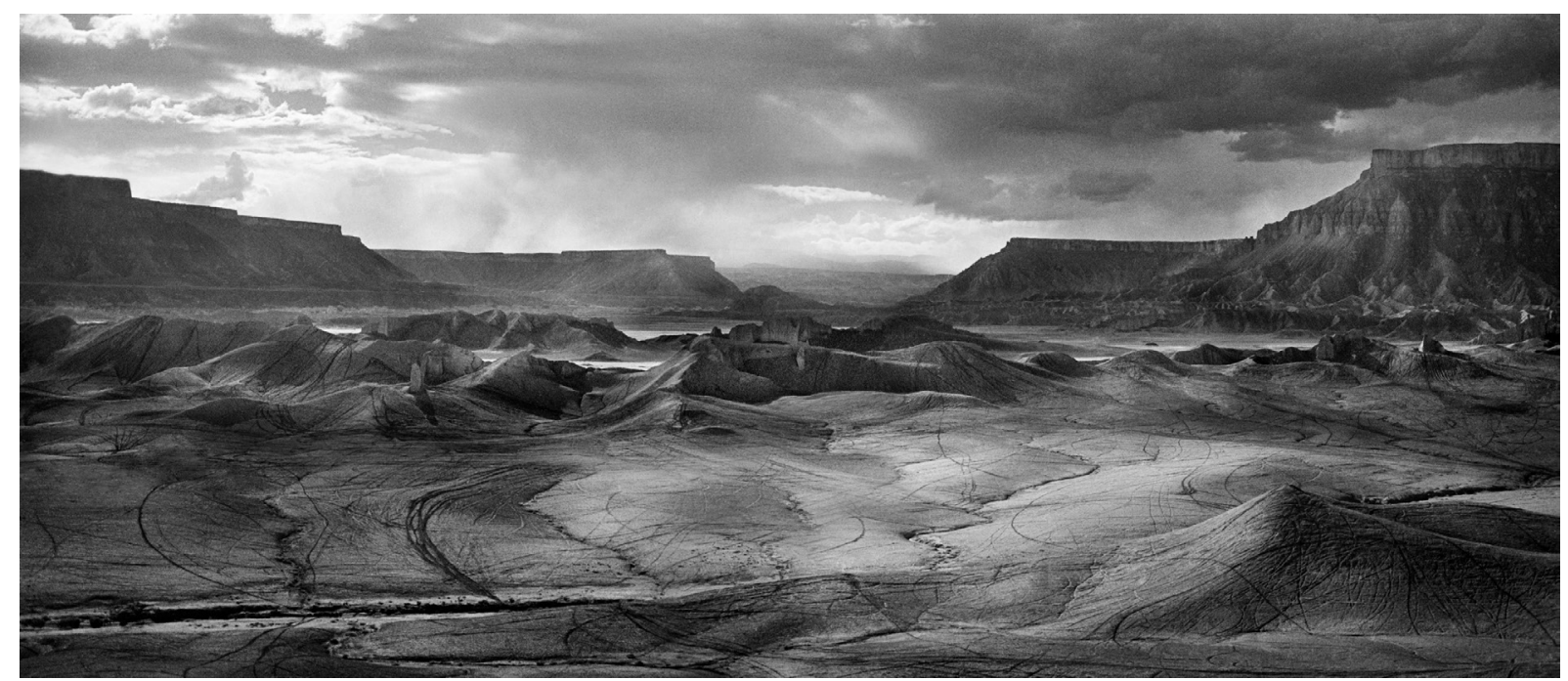

Fuente: @ Collection of the Tucson Museum of Art. Gift of Roderik Henderson. 2009.6. Cortesía del artista. 
En el año 2000, en la Royal Academy of Art, tuvo lugar la exposición Apocalypse: Beauty and Horror in Contemporary Art (Apocalipsis: belleza y horror en el arte contemporáneo), comisariada por el historiador del arte Norman Rosenthal. A pesar del aparente pesimismo que destila la temática abordada, resulta importante reflexionar sobre la importancia de la trama argumental de esta muestra. Es esencial adoptar una actitud receptiva al observar las obras, que permita que sus pensamientos entren en nuestra mente, transmitiéndonos un conocimiento más profundo de la propia existencia. Esta idea es planteada por Rosenthal, quien afirma que después de todo la anticipación del apocalipsis es un estado permanente (Sasse y Handlin, 2009).

\section{CONCLUSIONES}

El recorrido sobre el concepto de lo sublime inscrito en la creación fotográfica actual nos ha proporcionado diversas interpretaciones de esta acepción a través del discurso de artistas que comparten un interés común: el paisaje alterado por el hombre, calificado como paisaje antrópico. La selección de fotógrafos incluidos en este artículo revela una constante implícita en el trabajo de estos autores: el poder de la humanidad sobre la tierra como experiencia de lo sublime. Así pues, descubrimos cómo lo sublime está presente en el cambio de las cosas, asumiendo la ineludible condición performativa de un paisaje post-industrial que condiciona nuestra existencia.

Analizar lo sublime en el paisaje antrópico nos ha llevado a percibir el valor conceptual de la fotografía sobre su función documental. En la actualidad el fotógrafo es un explorador que indaga a través de su cámara las huellas de un mundo alterado por el ser humano, desvelándonos las claves implícitas en la estructura del paisaje. Es importante subrayar cómo el acto de fotografiar se convierte en una cuidadosa exploración, en la que el artista conecta física y espiritualmente con el entorno. Los fotógrafos analizados crean un profundo vínculo con el medio, ya sea este natural o urbano, proporcionándonos una lectura simbólica de su obra mediante la proyección de valores intangibles del entorno industrializado.
Aspectos inmateriales como el sentimiento de terror y dolor asociado a lo sublime brotan al percibir a través de la fotografía el mundo global y de naturaleza artificial que se impone ante nuestros ojos, algo que podemos constatar al visualizar los paisajes industriales de Edward Burtynsky o John Pfahl, las composiciones digitales de Andreas Gursky, o los vestigios desérticos de Richard Misrach. Todos los fotógrafos analizados abordan el poder de la industria, transfiriendo en el espectador sentimientos encontrados de atracción y repulsión, posicionándonos en puntos geográficos estratégicos que nos introducen de forma directa en la experiencia paisajística. Por tanto, la fotografía instiga una conexión emocional en el espectador. Esto es algo que persiguen también muchos de los fotógrafos incluidos, relacionados con lo sublime en la naturaleza. Hiroshi Sugimoto, Dana Fritz, Axel Hütte o Lynn Davis llevan a cabo una experimentación fotográfica que deviene en misteriosas atmósferas que nos envuelven y sugestionan.

La exploración y experimentación fotográfica simboliza un proceso de entendimiento en el que el artista forja la actual conceptualización del paisaje. Los fotógrafos documentan el mundo para entenderlo. Comprender el sentimiento encontrado de atracción y repulsión que provocan ciertas imágenes llega a ser realmente un reto en la actualidad, que nos lleva a reflexionar sobre qué nos afecta más: ¿la belleza estética o la catástrofe ambiental? El propio Edward Burtynsky reflexiona sobre este doble sentimiento que experimenta a través de sus fotografías.

Por último, tras indagar en las narrativas implícitas en la imagen fotográfica, advertimos su función educativa. La fotografía es una ventana abierta al mundo que nos muestra la realidad que trasciende tras la superficie de la imagen y nos introduce en una red de conexiones que impulsa nuestro conocimiento del entorno. Los fotógrafos Harry Callahan y Edward Weston ya se plantearon la función educativa de la cámara en otro tiempo, ya que ellos no la veían como una simple herramienta documental. La fotografía de paisaje es una entidad protagónica dentro del crecimiento de nuestra conciencia medioambiental, y por ende, puede ser considerada como objeto de aprendizaje y análisis del paisaje antrópico.

\section{NOTAS}

1 Afirmación literal realizada por el artista Andreas Gursky, y recogida en: Contactos. Los mejores fotógrafos del mundo revelan los secretos de su profesión.

2 Algunas obras de Elger Esser son: Pointe du Percho, France, de 2006, Tonnay I, France, de 1997, Doubt, France, de
1999, Combray (Merry-sur-Yonne), France, de 2008, o Poveglia, Italy, de 2001. Véase Gronert, 2009, pp. 51-52.

3 Cabe señalar las siguientes obras de Axel Hütte: Crucifix Lane II, London, de 1996; Furka, Switzerland, de 1995; Island Fo, Iceland, de 2002; Furka II,
Switzerland, de 1995; Mudchute II, England, de 2001; Stratosphere Tower, Las Vegas, USA, de 2003; Vetlebreen, Norway, de 2000; Nourlangie Billabong II, Australia, de 2000; Capulin, Fire I, USA, de 2007. Véase Gronert, 2009, pp. 29-30. 
4 Fragmento de la entrevista a Hiroshi Sugimoto (Cué, 2015)

5 Original en inglés: "l’m not interested in pushing simple opinions or making propagandistic statements. It seems to me that when more than one message is presented in a work of art, a tension is created that cries out for resolution. People who are conditioned by advertising photography and most photojournalism expect an unambiguous message and find my work perplexing. However, I would hope that most viewers are provoked by the deliberately fostered tension to think more deeply about the complexity of the issues. The intention is to make people relate to the implications of an image».

6 Original en inglés: "For beauty is only the beginning of terror... ».

7 Original en inglés: «The prodigious display of smoke bursting forth from the stacks of the Bethlehem Steel coke operation in Lackawanna, New York, can best be seen from a low slag bluff overlooking the plant from the north. A narrow boat channel of dark water separates me from the silhouetted factory buildings bathed in the radiance of Lake Erie. By the simplest act of looking through the enormous telephoto lens of my Hasselblad, I thrust myself into a phantasmagoria of light and color. Simultaneously attracted and repelled, I feel myself engulfed in a truly awesome spectacle of nature. It is like suddenly being hurled into a roaring cataract, an

\section{BIBLIOGRAFÍA}

Adams, R. (1996). Beauty in Photography. New York: Aperture.

Álvarez Areces, M. Á. (2009). Patrimonio, Cultura y Paisaje, recursos para una economía sostenible. Ambienta, 88, pp. 9-19. Disponible en http://www.iarca. net/pdf/patrimonio-cultura-y-paisaje.pdf

Beil, R. y Fessel, S. (2008). Andreas Gursky: Architecture. Hatje Cantz Verlag.

Berg, S., Bitterli, K., Campany, D., Gronert, S. e Imhof, D. (eds.) (2011). Through the Looking Brain. Eine Schweizer Sammlung konzeptueller Fotografie. Hatje Cantz.

Bodei, R. (2011). Paisajes sublimes. El hombre ante la naturaleza salvaje. Madrid: Siruela.

Bright, D. (1985). Of Mother Nature and Marlboro Men. An Inquiry into the Cul- eruption volcano, or a violent storm at sea. Alarm whistles blow and smoke discharges into the sky, expanding and changing form far more rapidly than I can imagine possible, and at its absolute zenith, dissipating into thin air before I can take another breath.

The presentation has its own geyserlike rhythms and rationale, and fifteen to twenty minutes pass before another discharge takes place. Doubtless, the efficiencies of the internal workings of the mill dictate a logic for the timings, but from my removed vantage point I can only see them as part of an irrational process, terrifying in its capriciousness. Dark, fuming emissions collide with brilliant, white pillows, both swept away in a moment by a thick, yellow vapor. I rotate my camera on its tripod hastily, moving its aim from one vortex of activity to another, trying to keep pace with the rapid transformations.

\section{[...]}

As the hours pass by and the sun lowers, pink and orange highlights ass their glow to the towering clouds of effluvium. Each hour, each day, each time of year holds its own surprises».

8 Original en inglés: «lf the human experience can be considered a manifestation of dreams, and desires, mines can be thought of as the source for the raw material of that experience. On one level of understanding that mineral rich ore is manufactured into the objects of our

tural Meanings of Landscape Photography. Exposure, 23, 1. Disponible en: http://www.deborahbright.net/PDF/ Bright-Marlboro.pdf

Cué, E. (2015). Entrevista a Hiroshi Sugimoto [En línea]. Disponible en http://www. alejandradeargos.com/index.php/es/ completas/9-invitados-con-arte/500sugimoto-entrevista-elena

Davis, K. F. (1999). An American Century of Photography: From Dry-Plate to Digital: The Hallmark Photographic Collection. Kansas City: Hallmark Cards.

Earle, E., Phillips, C., Squiers, C. y Wallis, B. (eds.) (2006). Ecotopia: The Second ICP Triennial of Photography and Video. Steidl/ International Center of Photography.

Ellsworth, E. y Kruse, J. (eds.) (2013). Making the Geologic Now: Responses to Ma- collective desire: the automobiles we drive, televisions we watch, jets that fly us around the globe, houses that provide us with shelter and comfort, and an endless stream of gadgets and goods. If gold, silver and diamonds are the valuables we bestow upon each other, to honour great citizens and profess our love, then are not the great voids we leave in that residual landscape a lasting testament to these ambitions? The imagery I derive from these landscapes therefore becomes symbolic. What this civilization leaves in the unwitting creation of gigantic monuments to our way of life».

9 Original en inglés: "I remember seeing my first Carleton Watkins prints at the Metropolitan Museum in New York in the early eighties. They were remarkable, with an aliveness in the images that is hard to find in contemporary work».

10 Original en inglés: «To feel and speak the astonishing beauty of things--earth, stone and water, beast, man and woman, sun, moon and stars--

The blood-shot beauty of human nature, its thoughts, frenzies and passions. And in human nature its towering reality...to feel greatly, and understand greatly, and express greatly, the natural beauty, is the sole business of poetry.

The rest's diversion... Many people of today are actually afraid of beauty! ». En Adams (1979).

terial Conditions of Contemporary Life. Brooklyn: Punctum books.

Foresta, M., Gould, S. J. y Marling, K. A. (1992). Between Home and Heaven. Contemporary American Landscape Photography. Smithsonian Institution / University of New Mexico Press.

Galassi, P. y Lowry, G. D. (2002). Andreas Gursky. New York: The Museum of Modern Art.

Gronert, S. (2009). The Düsseldorf School of Photography. London: Thames and Hudson.

Gursky, A., Bradley, F., Hilty, G. y Biggs, L. (1995). Andreas Gursky. Images. London: Tate Gallery.

Jussim, E. (1990). A Distanced Land: The Photographs of John Pfahl. New York: The University of New Mexico Press. 
Klein, W. (2011). Contactos. Los mejores fotógrafos del mundo revelan los secretos de su profesión [DVD]. Barcelona, 2011.

Klingender, F. D. (1947). Art and the Industrial Revolution. London: N. Carrington.

Mitchell, M. (2009). Australian Minescapes. Edward Burtynsky. Western Australian Museum.

Mitchel, M. y Rees, W. (2009). Edward Burtynsky: Oil. Steidl.

Ohlin, A. (2002). Andreas Gursky and the Contemporary Sublime. Art Journal, 61, 4, pp. 22-35.
Pauli, L. (2003). Manufactured Landscapes. The Photographs of Edward Burtynsky. Ottawa: National Gallery of Canada / Yale University Press.

Pratesi, L. y Carpi de Resmini, B. (2009) Espacios urbanos: Andreas Gursky, Candida Höfer, Axel Hütte, Thomas Ruff, Thomas Struth. Buenos Aires: Larivière.

Ruud, B. K. (2013). Encounters: Photography from the Sheldon Museum of Art. Lincoln: University of Nebraska Press.

Sasse, J. y Handlin, E (2009). Trouble in Paradise. Examining Discord between Nature and Society. Tucson: Tucson Museum of Art.

\section{Fuentes archivísticas}

Adams, A. (1979). Experimental Lecture F.O.P. 8-11-1979: My Life in Photography. En Activity files: Lectures, 1976-1983. Interviews, 1945-1978 (Ansel Adams Archive). Tucson, Arizona, Center for Creative Photography, Volkerding Study Center (Ref: AG31:2:14:6). 